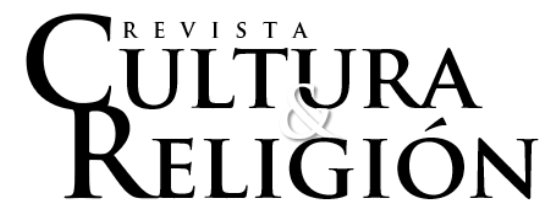

Vol. XV, N$^{\circ} 2$ (2021) pp. 210-243

Recibido: 19 de marzo de 2021

Aceptado: 30 de octubre de 2021

\title{
EL COSTO DE DISENTIR: ANÁLISIS DE EXPERIENCIAS DE RUPTURA DE EXMIEMBROS DE TRES IGLESIAS \\ PROTESTANTES
}

The cost of dissent: analysis of experiences of rupture of former members of three protestant churches

\section{Rafael Isaac Ramírez Macías*}

Centro de Enseñanza Técnica y Superior (Cetys), México

ORCID: 0000-0003-1058-7282

\section{Olga Odgers**}

El Colegio de la Frontera Norte, México

ORCID: 0000-0002-9656-8877

\section{Resumen}

El objetivo de este artículo es analizar las causas y consecuencias de la disidencia religiosa entre miembros de los Testigos de Jehová, de la Iglesia adventista y de la Iglesia de Jesucristo de los Santos de los Últimos Días. Desde una perspectiva fenomenológica, se observan las experiencias individuales reconstruyendo sus trayectorias mediante una metodología centrada en las

\footnotetext{
* Doctor en Estudios Culturales, El Colegio de la Frontera Norte, México. Catedrático en el Centro de Enseñanza Técnica y Superior (Cetys) en Tijuana, Baja California. Correo electrónico: rafaelrdesc2016@colef.mx

** Doctora en Sociología, Escuela de Estudios Superiores en Ciencias Sociales (EHESS), Francia. Investigadora de El Colegio de la Frontera Norte y miembro del Sistema Nacional de Investigadores (Nivel III) de la Academia Mexicana de Ciencias y de la Red de Investigadores del Fenómeno Religioso en México. Su investigación se centra en el estudio de la relación entre migración, religión y salud. Correo electrónico: odgers@colef.mx
} 
identidades narrativas. A partir de los casos analizados, observamos que en los tres casos de estudio las causas de la disidencia pueden ser teológicas o terrenales, el período entre el surgimiento de los desacuerdos y su expresión pública es extenso, y tener familiares en la misma congregación es el principal retardador de la confrontación. Las sanciones varían entre iglesias, pero el distanciamiento de personas afectivamente significativas es la consecuencia más difícil de sobrellevar -especialmente entre Testigos de Jehová. Por ello, quienes mantenían redes sociales fuera de la congregación antes de la ruptura, disponen de mayores recursos para hacer frente a las sanciones sociales y simbólicas.

Palabras clave: disidencia religiosa, Testigos de Jehová, adventistas, mormones, movilidad religiosa.

\section{Abstract}

The goal of this article is to analyze the causes and consequences of religious dissidence among members of the Jehovah's Witnesses, Adventist Church and Church of Jesus Christ of Latter Day Saints. From a phenomenological perspective, we observed individual experiences, rebuilding their pathways through a methodology focused on narrative identities. Based on the cases analyzed, we observed that the causes of dissidence in all three communities can be theological or earthly. The period between the emergence of disagreements and their public expression is extensive and having family within the same congregation is the main factor in delaying confrontation. Punishment varies from church to church but distancing from emotionally important people is the most difficult consequence to face, particularly for Jehovah's Witnesses. Those who maintain social networks outside of the congregation prior to breaking with it thus have more resources for facing the social and symbolic sanctions.

Ramírez, R. y Odgers, O. (2021). El costo de disentir: análisis de experiencias de ruptura de exmiembros de tres iglesias protestantes. Revista Cultura y Religión, 15(2), 210-243. 
Keywords: Religious dissidence, Jehovah's Witnesses, Adventists, Mormons, religions mobility.

\section{Introducción}

La relación entre adscripción religiosa y pertenencia a una comunidad ha sido un tema recurrente en la sociología de la religión. Para Durkheim ([1912] 1995), la función principal de la religión era crear comunidad, producir el "lien social" que fundamenta la existencia de la colectividad, siendo la creencia compartida y la ritualidad -ejercida colectivamente- los vínculos que permiten al individuo "ser y pertenecer". Esta idea, que considera la pertenencia a una comunidad creyente como vínculo primordial con la colectividad, prevalecerá hasta la segunda mitad del siglo XX, cuando nuevos marcos interpretativos propongan otras formas de relación entre creencia y pertenencia.

Davie (1990) destaca la normalización del "creer sin pertenecer" en la sociedad británica contemporánea. En contraste, "pertenecer sin creer" sigue siendo una posición problemática. Por su parte, con la finalidad de explicar la coexistencia, en las sociedades contemporáneas, del surgimiento de nuevos movimientos religiosos y del avance de los procesos de secularización/individuación, Hervieu-Léger (1993) propone una nueva aproximación al fenómeno religioso, observando la autoridad de la tradición que construye un linaje creyente como una respuesta ante la fragmentación de la memoria colectiva, está última fuente de producción de sentido colectivo. El linaje creyente posibilita la construcción de un sentido de pertenencia con quienes -en el pasado, presente y futuro- se adscriben a un sistema de creencias compartido. Así, la ruptura con la creencia significaría no solamente la pérdida de vínculos con una comunidad en tiempo presente, sino también la ruptura del linaje (Mora Duro, 2017).

Pero, ¿qué sucede, entonces, cuando surge el disenso? ¿Qué implicaciones tiene para el individuo expresar su desacuerdo con principios

Ramírez, R. y Odgers, O. (2021). El costo de disentir: análisis de experiencias de ruptura de exmiembros de tres iglesias protestantes. Revista Cultura y Religión, 15(2), 210-243. 
doctrinales, o con orientaciones prácticas que la Iglesia establece como normas? ¿Cuáles son las implicaciones, para el individuo, cuando sobreviene la ruptura del lien social, del linaje creyente o del sentido de pertenencia?

Para acercarnos a estas interrogantes, en este artículo se indaga la forma en que se gestiona el disenso y la ruptura en tres iglesias protestantes, frecuentemente agrupadas en México, para fines estadísticos, bajo la categoría "Bíblicas no evangélicas"1 (INEGI, 2015). Estas son la Iglesia de Jesucristo de los Santos de los Últimos Días (IJSUD) (conocidos como mormones), la Iglesia Adventista del Séptimo Día y los Testigos de Jehová. Se seleccionaron estas tres iglesias, debido a que en su estructura organizativa existe una regulación precisa y rigurosa para indicar quién pertenece a la comunidad de creyentes $-\mathrm{y}$ en qué función-, y quién deja de pertenecer a esta.

La investigación se realizó en Tijuana, Baja California (México). El abordaje metodológico fue cualitativo, centrado en el análisis de entrevistas en profundidad con exTestigos de Jehová, exmiembros de la IJSUD y exmiembros de la Iglesia Adventista. ${ }^{2}$ De manera complementaria, se entrevistó a dirigentes y miembros activos de las iglesias estudiadas. Partimos de la perspectiva teórico-metodológica de las identidades narrativas (Andrews, 2002; Bruner, 2002) y asumimos que las personas se construyen a través de sus relatos, por lo que presentar su relato biográfico exige al creyente un trabajo de selección de los sucesos relatados, en busca de su resignificación dentro de una trama coherente, que le permita enunciar quién era, quién es ahora y quién desea ser

1 Retomamos esta categoría del Censo de Población del año 2010, en el que la etiqueta "Bíblicas no evangélicas" agrupa a las tres denominaciones objeto de este estudio. Más allá de las críticas que pudiera hacerse a dicha etiqueta, las tres denominaciones ahí agrupadas comparten las características necesarias para el análisis que aquí nos proponemos: son iglesias que, aunque minoritarias en nuestro país, han experimentado un crecimiento notable en las últimas décadas, tienen prácticas de socialización ritual bien establecidas, y definen con rigor y precisión quién pertenece a la comunidad y quién se encuentra fuera de ella.

2 Según el Censo Nacional de Población y Vivienda del año 2020, en la actualidad el porcentaje de adscripción a las iglesias estudiadas, en el municipio de Tijuana, B.C., es de 54.421 personas (8.489 adventistas, 7.628 IJSUD y 38.304 Testigos de Jehová), lo que en conjunto representa el $2,8 \%$ de la población total.

Ramírez, R. y Odgers, O. (2021). El costo de disentir: análisis de experiencias de ruptura de exmiembros de tres iglesias protestantes. Revista Cultura y Religión, 15(2), 210-243. 
en el futuro. Asimismo, nuestro análisis se nutre de otros estudios centrados en la experiencia vivida (Cantón, 2009), la relación entre identidades y linaje creyente (Medina, 2020) y la autoetnografía (Sánchez, Plascencia y Bernal, 2020). Las entrevistas fueron transcritas y codificadas para la realización de un análisis temático, cuyos ejes principales fueron: la razón del disenso, la forma en que este se expresó ante la Iglesia, el proceso de ruptura, las sanciones y sus consecuencias; todo esto desde la perspectiva del sujeto disidente. Así, las entrevistas realizadas permiten aproximarnos a la interpretación de los sujetos acerca de la forma en que consideran que la decisión de disentir contribuyó a forjar la persona que ahora cada uno es.

Para presentar los resultados obtenidos, comenzaremos por discutir la disidencia religiosa como categoría analítica; después presentaremos algunos elementos centrales de los relatos biográficos centrándonos en las causas y expresiones del disenso y la ruptura; el tercer apartado analiza las sanciones y las consecuencias de la ruptura. Finalmente, concluimos con algunas reflexiones comparativas, abordando algunos aspectos necesarios para entender por qué las consecuencias de la ruptura difieren significativamente en la vida de las personas que levantan la voz para disentir.

\section{Nuevas coordenadas para repensar la disidencia religiosa}

La presente investigación ${ }^{3}$ surgió del interés por estudiar las relaciones de poder ejercido y la disidencia religiosa al interior de grupos bíblicos distintos de los evangélicos. Específicamente, se planteó indagar, desde el relato autobiográfico, cómo los sujetos que han realizado actos disidentes, posicionan sus propias acciones, expresan los motivos que los llevaron a disentir, y narran las repercusiones que las sanciones impuestas y la ruptura tuvieron en su biografía.

${ }^{3}$ La tesis doctoral realizada por Rafael Ramírez con una beca Conacyt, es el punto de partida para la investigación que aquí se presenta.

Ramírez, R. y Odgers, O. (2021). El costo de disentir: análisis de experiencias de ruptura de exmiembros de tres iglesias protestantes. Revista Cultura y Religión, 15(2), 210-243. 
El concepto de disidencia es entendido como el desacuerdo intelectual con las ideas, doctrinas, actividades o creencias promovidas por un grupo o sistema de pensamiento al que se pertenece por voluntad o nacimiento. ${ }^{4} \mathrm{La}$ conversión religiosa implica también una separación, además de un proceso de resocialización (Hernández, 2011, p. 141); sin embargo, dicha separación podría ser progresiva y no confrontativa, por lo que conviene no confundirla con la disidencia.

Los actos de disidencia religiosa pueden ser individuales o colectivos. Desde la perspectiva individual, se disiente como expresión de desacuerdo personal frente al grupo, sin pretensión de crear una comunidad de disidentes, escindir la Iglesia o generar movilidad religiosa grupal. Aun cuando el acto disidente per se tenga una intención contestataria frente a lo establecido, la disidencia individual no implica la creación de una nueva comunidad que reforme la fe o escinda al grupo. En contraste, la disidencia colectiva se asocia con una intención reformista o cismática. Aquí la disidencia no solo es externalizada con intenciones de protesta, sino que se cuestionan las normas con intenciones de reforma institucional y se propone el abandono agrupado o la separación cismática. En este estudio se analizan procesos de disidencia individual y no de disidencias colectivas; sin embargo, es conveniente tener en cuenta el origen cismático de las tres iglesias mencionadas.

La idea de disidencia -en el campo religioso- es cercana a las nociones de apostasía, desacuerdo, protesta y rebeldía. Se trata de conceptos asignados a la acción de diferir de las ideas dominantes y de externarlos de alguna manera perceptible. Diversos autores han propuesto aproximaciones analíticas para comprender los actos de disidencia y los procesos de abandono de las iglesias o congregaciones a las que se pertenecía.

\footnotetext{
${ }^{4}$ La conversión también podría considerarse como una forma de ruptura cuando se cambia de una religión a otra, pues podría implicar una resocialización que conlleve cambios en la realidad subjetiva.
}

Ramírez, R. y Odgers, O. (2021). El costo de disentir: análisis de experiencias de ruptura de exmiembros de tres iglesias protestantes. Revista Cultura y Religión, 15(2), 210-243. 
Arroyo (2004) considera que la transformación cultural, el avance de la modernidad tecnificada, el pluralismo cultural, la secularización y la modernización influyen en las tendencias y en las formas en que se presenta la religiosidad en la sociedad, pudiendo generar factores de disenso. Desde esta perspectiva, la disidencia estaría vinculada al abandono de la religiosidad encuadrada por la Iglesia, ya sea por el proceso de individuación de la creencia (Hervieu-Léger, 1993), por la adopción de un modelo de creencia sin pertenencia (Davie, 1990), o por el abandono de la creencia. Dentro de esta perspectiva está menos presente la disidencia reformista, de escisión, o de movilidad religiosa.

Siguiendo los planteamientos de Mora Duro basados en el trabajo de Hervieu-Léger, (1996, p. 28), el primero propone considerar la disidencia religiosa como la ruptura del linaje creyente:

La desafiliación religiosa puede, entonces, manifestarse como una falta de identificación o, incluso, como un tipo de aversión directa hacia un 'linaje creyente', ya que la persona expresa una falta de continuidad respecto a 'una comunidad que reúne a los creyentes pasados, presentes y futuros'. (Mora Duro, 2017, p. 162)

En contraste, Casillas (1988) señala que las disidencias de corte protestante pueden ser vehículos para expresar inconformidades no religiosas y relativas a un conflicto con la jerarquía. En esta modalidad disidente es posible que el movimiento adquiera una dimensión colectiva y la ruptura signifique la salida de parte de la congregación, y no de un individuo aislado.

Por su parte, Corpus (2014: 42) propone que entre los jóvenes mexicanos la disidencia podría relacionarse con el desplazamiento de la búsqueda de sentido de pertenencia hacia otros referentes no religiosos. Otro aspecto a considerar en este grupo de edad serían las etapas de la vida -la adolescencia y en la adultez emergente-, marcadas "por el desprendimiento de la familia y de la práctica religiosa en grupo" (Sánchez, Plascencia y Bernal, 2020, p. 128).

Ramírez, R. y Odgers, O. (2021). El costo de disentir: análisis de experiencias de ruptura de exmiembros de tres iglesias protestantes. Revista Cultura y Religión, 15(2), 210-243. 
Rambo (1993) y Gooren (2010) proponen situar el estudio de los procesos de disidencia dentro de una perspectiva temporal amplia: la carrera o trayectoria del creyente. Los actos disidentes pueden comprenderse entonces como la culminación de un largo proceso, que transita de la duda o el desacuerdo no expresado a la ruptura. En ese sentido, es importante señalar que la disidencia es un atributo de los actos que muestran el disenso, y no de los sujetos que los realizan, ya que el disenso y la ruptura deben ser analizados como momentos específicos dentro de una trayectoria en la que la creencia y la pertenencia se transforman. Así, hablar de un individuo disidente, lejos de ayudar a la comprensión del proceso de disidencia y ruptura, esencializa al sujeto: el disidente no es alguien que tenga una identidad permanente como tal, sino un individuo que en algún momento puntual de su vida decidió expresar su desacuerdo mediante uno o más actos disidentes. El acto disidente -por implicación lógica- se realiza frente a un poder hegemónico que dicta formas “correctas" de actuar y establece límites de conducta a los que participen de su esfera de control.

Esta perspectiva es coherente con la idea de movilidad religiosa como un proceso al que, en la dirección inversa, Hernández-Madrid (2000) denomina el proceso de convertirse en creyente. De esta forma, entendemos la disidencia como un caso particular dentro de la diversidad de formas de movilidad religiosa (Garma y Odgers, 2021).

Un elemento común entre la experiencia de disidencia y ruptura y la de movilidad religiosa es que estas se viven de manera individual como procesos de mediana o larga duración. No ocurre de la noche a la mañana que los sujetos despierten con una conciencia nueva de su situación en el mundo que transforme su fe, sino que tales procesos de transformación religiosa personal son paulatinos y secuenciales. Incluso lo que Garma denomina “conversión paulina“ es interpretado por él mismo no como una transformación repentina, sino como una manera de narrar múltiples experiencias vividas por el individuo a lo largo del tiempo de una forma en que sea útil a los no conversos, para dar

Ramírez, R. y Odgers, O. (2021). El costo de disentir: análisis de experiencias de ruptura de exmiembros de tres iglesias protestantes. Revista Cultura y Religión, 15(2), 210-243. 
testimonio de la fe y para adecuar la vida de los conversos a las expectativas de la congregación, siguiendo un notable relato bíblico de conversión (Garma, 2018, pp. 104-108).

La disidencia implica una trayectoria que incorpora momentos de crisis de lo que se creía como verdadero, hasta desembocar en acciones disidentes (actos puntuales que cuestionan lo establecido con intenciones reformistas, cismáticas o apóstatas). El acto disidente es un momento culminante para el afiliado a una comunidad religiosa, que entra en conflicto frontal con ella. El conflicto puede llevar a la ruptura, pero no todas las experiencias de salida de la Iglesia se producen mediante la disidencia.

Rambo (1993) y Gooren (2010) coinciden al señalar que es importante comprender los "tipos de abandono" religioso. La intencionalidad del sujeto y las modalidades de la ruptura resultan centrales para entender esta diferenciación. El primer autor considera los conceptos de apostasía y defección (o deserción) de un grupo religioso dentro de la misma categoría de análisis (1993, p. 13), posiblemente entendiendo que la defección es la acción de abandonar una fe y a una comunidad religiosa a la que se había jurado lealtad y que, en consecuencia, el sujeto será visto como desleal. Dentro de esta interpretación, el disidente se asemeja al apostata.

En contraste, Garma (2018, pp. 115-118) destaca que no todas las formas de abandono de la fe son juzgadas de igual modo: la nueva posición que tome el individuo al salir de la congregación de origen será crucial. Por ejemplo, un Testigo de Jehová que abandona su iglesia para participar de otra comunidad religiosa, en todos los casos, será visto como apóstata. En cambio, un miembro de una iglesia pentecostal que abandona su comunidad para unirse a otra iglesia protestante o evangélica no será considerado como apóstata, sino como "hermano separado“, siempre y cuando no mantenga una posición activa de rechazo a la institución religiosa que ha abandonado (Garma, 2018).

Aunque la institución religiosa pueda ver a algunos miembros que han abandonado su iglesia como "caídos" o "hermanos separados" de los cuales

Ramírez, R. y Odgers, O. (2021). El costo de disentir: análisis de experiencias de ruptura de exmiembros de tres iglesias protestantes. Revista Cultura y Religión, 15(2), 210-243. 
espera su regreso (Garma, 2018), el acto de abandono de un grupo religioso implica en sí mismo, para quien se separa, un acto de disidencia. Insistimos en que, desde esta perspectiva, el abandono puede darse sin que exista un desacuerdo doctrinal.

A diferencia de lo planteado por Rambo (1993), el término apostasía es entendido por Garma no solo como una posición teológica, sino, además, como un acto de oposición a la "religión verdadera", diferenciándolo de quien se aleja, sin oposición.

Una persona puede abandonar la Iglesia e incluso renunciar a sus creencias, pero puede salir de la congregación con respeto y sin atacarla. Quizá, incluso, ya no cree en nada, pero no agrede a la institución. Se espera que algún día dicha persona pueda regresar (...). Pero el apóstata, por sus actos, "ha quemado todas las naves" y deja claro que la reconciliación ya no es posible. El apóstata inevitablemente cae en la herejía, porque sus ataques y agresiones muestran su rechazo de la fe verdadera. (Garma, 2018, s. p.)

Para Rambo (1993), la apostasía o defección se vincula con los planteamientos generales del paradigma de la secularización, ya que ve la disidencia como un abandono de la fe y no necesariamente como la sustitución de una creencia por otra.

Como notamos en las definiciones anteriores, la apostasía apunta a un rechazo, repudio o herejía. Pero también está el factor del abandono, que puede darse como enfriamiento o alejamiento gradual, sin enfrentamientos. Así, surge la pregunta: ¿quién determina si una deserción de un grupo religioso "es con respeto y sin atacar a la Iglesia" (Garma, 2018), o si se trata de un acto de repudio o agresión?

Para los fines de este estudio, centrado metodológicamente en las narrativas biográficas de quienes realizan actos disidentes, importará su propia interpretación de los hechos. La valoración de la institución religiosa hacia el acto disidente estará considerada solamente en un segundo momento, al

Ramírez, R. y Odgers, O. (2021). El costo de disentir: análisis de experiencias de ruptura de exmiembros de tres iglesias protestantes. Revista Cultura y Religión, 15(2), 210-243. 
analizar las sanciones que se impusieron al "disidente", y las consecuencias de dichas sanciones en el relato biográfico de quien las recibe.

Con respecto a las sanciones impuestas, Garma (2018) y Gooren, (2010, pp. 70-76) recuerdan la necesidad de considerar las relaciones de parentesco en los procesos de disidencia y ruptura. El parentesco puede estar ligado a querer continuar en la religión parental por empatía, respeto o nostalgia; al éxito o fracaso de una conversión; al cambio a otra fe o iglesia; a la pérdida de la afiliación; y a la actividad en dos grupos religiosos distintos. El distanciamiento de otros miembros de la familia pertenecientes a la congregación, y la pérdida de la red social tejida en torno a la comunidad de la iglesia, es visto como un fuerte precio a pagar por quien disiente públicamente.

Finalmente, con relación a las instituciones religiosas que otorgan un lugar prominente a la lectura e interpretación de la Biblia, es útil recordar que dentro de la tradición bíblica cristiana primitiva se destacan tres tipos potenciales de abandono de la fe: la que ocurre por temor a la violencia o al sufrimiento, a ser torturado o perder la vida (I Pedro: 4); la que es involuntaria por motivos de "debilidad de la carne" (I Corintios: 6); y, la que es por voluntad propia o pérdida de la fe (Hebreos 6; 10; II Pedro: 2). Solo la última es vista como apostasía.

A partir de lo hasta aquí expuesto, centramos nuestro análisis en la trayectoria de los individuos que, desde sus relatos autobiográficos, consideran haber realizado actos disidentes. Es necesario que una acción reúna tres elementos para poder ser considerada un acto disidente: el sujeto que lo realiza pertenece al grupo en cuestión (se reconoce y es reconocido como miembro); hay una intencionalidad transgresora; y la acción es perceptible para los miembros del grupo. Así, el acto disidente implica: pertenencia (al grupo), intencionalidad (del actor) y perceptibilidad (del acto).

Sobre la base de lo observado, entenderemos como apostasía todo abandono voluntario de las instituciones religiosas, no motivado por temor, incapacidad o "debilidad", sino por libre elección. La relajación en el

Ramírez, R. y Odgers, O. (2021). El costo de disentir: análisis de experiencias de ruptura de exmiembros de tres iglesias protestantes. Revista Cultura y Religión, 15(2), 210-243. 
seguimiento de las normas y el paulatino distanciamiento de las iglesias no serán considerados actos disidentes, puesto que no cumplen con las características antes señaladas. Pero el abandono de la comunidad religiosa por pérdida de fe (libre elección manifiesta de no pertenecer), o por desacuerdos teológicos, morales o de procedimientos, expresados públicamente, sí lo será.

La salida de un individuo de la congregación en la que participaba puede darse por diversos motivos. Conviene distinguir la desafiliación y la defección o abandono, como categorías analíticas para comprender procesos de ruptura disímiles. La desafiliación se entiende como dejar de pertenecer a una Iglesia por motivos tales como la pérdida de fe, el enfriamiento espiritual, no poder cumplir las normativas, etc. Se trata de una pérdida de afiliación no confrontativa, en la que el individuo puede justificar sus acciones $-\mathrm{o}$ cuando menos, lo intenta-, no reniega de su antigua fe y solo toma distancia. Es un concepto útil para analizar la movilidad religiosa no tendiente a la apostasía.

La defección o abandono deliberado y argumentado ante la comunidad es distinto ontológicamente. Este se interpreta como apostasía, como un acto intencionado de rebeldía, de enfrentar a la Iglesia, de ilustrar a los demás con el ejemplo del camino a seguir. Por tanto, los actos disidentes frente a las estructuras de poder que aquí se analizan, en que los distanciamientos de las iglesias implican una intencionalidad transgresora, corresponden antes a la defección o apostasía que a la desafiliación.

A continuación, presentaremos algunos elementos de las trayectorias analizadas para mostrar los procesos de formación del disenso, su expresión pública (los actos disidentes), la ruptura y las sanciones recibidas. Recordemos una vez más que el análisis se centra en la interpretación que el propio sujeto hace de su experiencia.

Ramírez, R. y Odgers, O. (2021). El costo de disentir: análisis de experiencias de ruptura de exmiembros de tres iglesias protestantes. Revista Cultura y Religión, 15(2), 210-243. 


\section{Relatos de disenso y ruptura. Los casos de estudio}

Para analizar la experiencia de la disidencia desde los relatos biográficos, procedimos a localizar a personas que cumplieran con los siguientes criterios de inclusión: ser mayor de edad, haberse considerada parte de alguna de las iglesias analizadas (Testigos de Jehová, IJSUD, Adventistas del Séptimo Día) y haber sido reconocidas como miembros por las autoridades respectivas, haber realizado actos disidentes (cumpliendo los criterios de pertenencia, intencionalidad y perceptibilidad), y que a raíz de dichos actos se hayan separado de la congregación, ya fuera para formar parte de otra comunidad religiosa o no.

La localización de personas que cumplieran estos criterios no fue sencilla, debido a que, a diferencia de los miembros activos de una misma denominación religiosa, los "disidentes" no tienen ninguna visibilidad particular, no forman redes entre ellos ni comparten espacios de socialización. Adicionalmente, debido al carácter confrontativo del acto disidente, las dirigencias de las respectivas iglesias no conservan datos de contacto de los disidentes o no desean compartirlos. Dicho de otra forma, para la realización de la investigación empírica, en este caso no era posible acudir a ningún centro de culto para contactar a disidentes, ni seguir la técnica de bola de nieve. En consecuencia, fue necesario recurrir a una amplia red, dentro y fuera de las iglesias mencionadas, para localizar a los participantes. Consecuentemente, las personas entrevistadas no se conocen entre sí, e incluso, declararon no conocer a otras personas "disidentes".

Nuestra investigación no busca la representatividad estadística de la población desafiliada de las iglesias estudiadas. En cambio, se buscó una diversidad de perfiles con relación al sexo, la edad, la ocupación, para tener un espectro amplio a través del cual visualizar la composición de las distintas causas y consecuencias de la disidencia religiosa.

Con respecto al lugar de origen de los participantes, por el contrario, se buscó cierta homogeneidad: la totalidad de los entrevistados nacieron en

Ramírez, R. y Odgers, O. (2021). El costo de disentir: análisis de experiencias de ruptura de exmiembros de tres iglesias protestantes. Revista Cultura y Religión, 15(2), 210-243. 
Tijuana o llegaron a esta ciudad a edad temprana, y residían en esta ciudad al momento de la entrevista. Asimismo, todos fueron socializados, desde su infancia temprana, en los grupos religiosos de los cuales disintieron y al menos uno de sus padres pertenecían a sus iglesias de formación.

A continuación, se presentan de manera sintética los relatos biográficos de los seis participantes. Rescatamos particularmente aspectos de sus trayectorias como creyentes, previa al inicio de la etapa de disidencia; del proceso que lleva a la ruptura, así como del resultado de la misma a través de la posición con la que los entrevistados se autodefinen respecto a las iglesias de las que formaron parte; asimismo, presentamos elementos de sus actuales posturas respecto a las iglesias que abandonaron, detallando sus entornos familiares, y se aborda el relato de las consecuencias de la ruptura, que se expresan como pérdidas sociales y simbólicas, y como adversidades emocionales.

\section{Antonio (IJSUD)}

Antonio es un hombre de 37 años, originario de Tijuana. Su formación religiosa se dio en la IJSUD, a la que pertenecía su familia. A los 12 años fue bautizado y junto a su familia decidió llevar el proceso de "sellamiento" en un templo en California. Cuenta que el primer conflicto del que tiene memoria surgió por causa del diezmo que su padre aportaba, y que Antonio consideraba excesivo: calcula que su padre aportaba entre 40 y 50 mil pesos mensuales. En su relato, la segunda confrontación ocurrió cuando, dentro de su formación religiosa en la Iglesia, llegó el momento de hablar de sexualidad. Explica que se sintió incómodo por el hecho de que los dirigentes de su Iglesia querían controlar incluso temas íntimos, como la masturbación. Señala que vivió ese episodio como un intento de coerción y búsqueda de control sobre su cuerpo, por lo que decidió revelarse, mintiendo y desdeñando la educación sexual que se le intentó imponer.

Ramírez, R. y Odgers, O. (2021). El costo de disentir: análisis de experiencias de ruptura de exmiembros de tres iglesias protestantes. Revista Cultura y Religión, 15(2), 210-243. 
La primera situación como incómoda fue antes del sellamiento que tienes que pasar por una entrevista, que es como una especie de confesión en la Iglesia católica. Pasas con el obispo que en la Iglesia católica sería el sacerdote. Yo era un adolescente de 12 años, inexperto sexualmente, obviamente. Tal vez para el canon actual eso ya no sea normal (risas), pero en ese momento yo era inexperto... Bueno, él (el obispo) siento que me hizo una entrevista muy frontal, ¿no?, siempre mirándome a la cara (...). Y recuerdo que a los 15 o 20 minutos de la entrevista me miró fijamente, porque estás tú solo con él, y..., me empezó a hablar de mi adolescencia, de los cambios que sufre mi cuerpo... y me preguntó directamente: “¿Te masturbas?, ¿Haces tocamientos a tu cuerpo?” ... Sin dudar le dije que no. Pero yo ya había comenzado la exploración con mi cuerpo. Y recuerdo que fue incómodo, yo me dije: “¿Qué le voy a decir yo a este tipo?; ¿quién es?” (risas). No, o sea, es algo muy privado, ¿no? Ahorita lo comento ya con risa, pero en ese momento sí fue algo así como..., y luego, me dije: "Si no le digo lo que espera, no me va a dar su recomendación para poder sellarme con mis papás", así que le mentí. Le dije que no y lo miré a los ojos y no sentí ningún remordimiento porque me molestó, ¡me molestó! (Antonio, comunicación personal, 21 de enero de 2018).

Sin embargo, para Antonio el tema que terminó por desatar el conflicto fue cuando a los 18 años se le exigió cumplir con la función de misionero. Explica que, a diferencia de los acontecimientos anteriores, en esta etapa de su vida optó por la confrontación. Se negó abiertamente a realizar el servicio misionero incluso cuando vinieron altos cargos de la Iglesia a persuadirlo. Este fue el punto de ruptura definitivo para él. A partir de ese momento, el enfrentamiento con la Iglesia fue frontal. Esa confrontación vendría acompañada de un distanciamiento progresivo de la Iglesia, expresando abiertamente los motivos para hacerlo.

En el relato, esta etapa converge con la vida universitaria, que es cuando Antonio señala que aparecen sus primeras dudas teológicas. Comienza a

Ramírez, R. y Odgers, O. (2021). El costo de disentir: análisis de experiencias de ruptura de exmiembros de tres iglesias protestantes. Revista Cultura y Religión, 15(2), 210-243. 
preguntarse si los mormones realmente eran la religión verdadera, si el Libro del Mormón era de origen divino o incluso si dios existía como ente real.

Antonio culmina el relato de la disidencia y ruptura señalando que ha dejado de creer en la existencia de un creador supremo y ahora ve a la Iglesia como un nido de intereses y pugnas políticas por el poder.

\section{$\operatorname{Erika}(I J S U D)$}

Erika es una mujer soltera de 27 años, originaria de Tijuana. En su relato cuenta que, aunque tuvo una formación religiosa desde su infancia en la IJSUD, nunca sentía un contacto con lo divino, con una parte espiritual o trascendente en su ser. Explica que ese fue el motivo principal por el que comenzó su distanciamiento de la Iglesia, y que ese proceso vino acompañado por dudas teológicas referentes al origen divino de esta.

En su testimonio da muestras de que no le faltaban motivaciones para asistir a la iglesia, pero eran fundamentalmente de carácter social o por necesidades afectivas, más que por convicciones religiosas. Explica que el paso a la confrontación se dio por las restricciones impuestas por la Iglesia para buscar pareja sentimental exclusivamente entre los miembros de la comunidad religiosa, junto con, señala, la falta de equidad de género de la que fue testigo. La escasa capacitación de los clérigos para resolver sus preguntas y liderar al grupo exacerbaron el conflicto.

Relata que al principio solamente emitió protestas verbales ante su familia y otros miembros de la Iglesia. Más tarde, sin embargo, realizó actos que ella misma considera disidentes: propaganda antirreligiosa en redes sociales y desobediencia general en temas de alimentación, música, cine, vestimenta, lecturas, etc. $\mathrm{Su}$ proceso concluyó con el abandono deliberado de la Iglesia. Erika considera que su ejemplo sirvió a algunos miembros de su familia para relajar su conducta referente a las normas que les imponía la Iglesia.

Ramírez, R. y Odgers, O. (2021). El costo de disentir: análisis de experiencias de ruptura de exmiembros de tres iglesias protestantes. Revista Cultura y Religión, 15(2), 210-243. 


\section{Hernán (Adventistas del Séptimo Día)}

Hernán es un hombre homosexual de 47 años, nacido en Tijuana. Vive en unión libre con su novio, con quien tiene una relación monogámica estable y prolongada. En su relato, menciona que su educación religiosa se dio en la Iglesia adventista, adonde acudía con su familia. Se bautizó a los 12 años y se mantuvo como miembro activo hasta su mayoría de edad. Explica que, con el transcurso del tiempo, dentro de la Iglesia aparecieron situaciones que resultaron muy incómodas para él. En particular, le molestaba la actitud asumida por los líderes de la Iglesia respecto a la vigilancia estricta de la conducta de los jóvenes, y recuerda con enojo la presión y el chantaje que ejercían sobre él para que confesara actos transgresores propios, o incluso para que denunciara las transgresiones cometidas por otros miembros de la comunidad de fieles. También señala que le enojaba que pusieran en ridículo frente a la Iglesia a quienes habían quebrantado las normas del grupo. Adicionalmente, manifiesta su malestar por las hipocresías de algunos miembros de la Iglesia, la discriminación por clase social y por inclinación sexual. Describe su situación de la siguiente manera:

Yo creo que todo comenzó por una chava que salió embarazada. Y ya sabes: salir embarazada sin estar casada y de alguien de fuera de la Iglesia era un pecado grave. Y ella dijo: "Pero es que hay muchos de aquí que también salen y hacen cosas fuera de la Iglesia, y no les dicen nada*. Entonces eso desató la cacería de brujas, donde nos empezaron a llamar y a decirnos que nos habían visto en determinado lugar y que nos habían visto tomando y que ¿qué estábamos haciendo ahí? Y te lo digo porque esas preguntas me las hicieron a mí. Me aislaron, me pidieron que fuera a una junta y me empezaron a preguntar. Todo era como: "entonces ayúdanos, dinos a quién has visto, qué han hecho". Todo era para ver qué me podían sacar y hasta dónde iba a caer. Y eso a mí no me gustó porque todo era nada más acusar, para ver a quién echaba de cabeza. Y esa fue la causa principal que a mí me empezó a desmotivar muchísimo porque fue como quitarme la venda... que las personas que te están guiando y te

Ramírez, R. y Odgers, O. (2021). El costo de disentir: análisis de experiencias de ruptura de exmiembros de tres iglesias protestantes. Revista Cultura y Religión, 15(2), 210-243. 
están educando para que sigas un rumbo correcto, son personas muy torcidas (...). Es que tienes cierto respeto y cierta admiración por las personas y cuando pierdes eso, es muy difícil que lo puedas recuperar. Es como una traición. (Hernán, comunicación personal, 19 de febrero del 2018).

Desde entonces, Hernán comenzó a distanciarse de la Iglesia. Paralelamente, hizo lazos de amistad por fuera con compañeros del trabajo. Dentro de ese círculo social fue donde despertó su inquietud respecto a su inclinación sexual. Sus acciones transgresoras se iniciaron en esa etapa: salidas a centros nocturnos, consumo de alcohol y asistencia a los cines. Posteriormente, concretó su unión libre con una pareja homosexual. En su relato, en esta etapa de la vida expresó su desagrado hacia los líderes de la Iglesia por sus formas de proceder y sancionar las transgresiones, lo que culminó con su abandono deliberado de la Iglesia, externando sus motivos ante su familia. Hernán cuenta que más tarde su madre, su hermano y algunos de sus amigos, también abandonaron la Iglesia, aunque no sabe si la decisión de ellos fue influenciada por él. Así, en el relato de Hernán, la ruptura con la Iglesia no viene acompañada de un cuestionamiento sobre la fe-que conserva. El conflicto se centra en la relación con los líderes de su iglesia.

\section{Rodrigo (Adventistas del Séptimo Día)}

Rodrigo es un hombre de 31 años, originario de Sinaloa, que ha residido en Tijuana desde los 4 años. Antes de que cumpliera los 8, ya asistía junto a su familia a la Iglesia adventista. En su relato, explica que el motivo central del distanciamiento fue la discrepancia con actitudes de miembros de la iglesia, ya fueran los líderes o el resto de la comunidad. Los hechos específicos que menciona son el manejo de los diezmos, las sanciones aplicadas de manera desigual, la segregación por clase social, las pugnas políticas respecto a las jerarquías al interior de la iglesia, la discriminación y la protección a miembros de esta que habían cometido delitos sexuales.

Ramírez, R. y Odgers, O. (2021). El costo de disentir: análisis de experiencias de ruptura de exmiembros de tres iglesias protestantes. Revista Cultura y Religión, 15(2), 210-243. 
Rodrigo narra que fue expulsado de la Iglesia adventista en su etapa universitaria, pero para entonces ya llevaba unos cinco años de haberse distanciado. Explica que durante el tiempo en el que él se había distanciado de la Iglesia (pero antes de la expulsión), el pastor y el anciano de su iglesia realizaban visitas continuas a su casa, porque su madre seguía siendo miembro activo y responsable del área de salud de la Iglesia. En estas visitas dialogaban con él respecto a su condición dentro de la Iglesia. Rodrigo relata que en una de estas conversaciones, tanto él como su hermana encararon a los líderes religiosos respecto a sus desacuerdos y solicitaron verbalmente ya no pertenecer a la asociación, por lo que ambos fueron expulsados.

Los actos de confrontación que relata son burlas ocasionales sobre las restricciones alimentarias estipuladas por la Iglesia, y el invitar a otros miembros a consumirlos. También confrontó a su madre, al anciano y al pastor por el tema del ocultamiento de delitos sexuales ante las autoridades civiles.

Otra cosa que no me gustaba era la protección tan grande que tenían; a mí lo que me marcó muy canijo es que mi profesor de sexto año de educación física [...] violó a una niña y a un niño, y en esto mi mamá estuvo incluida porque era la encargada en salud, y decidieron no denunciar porque "Cristo juzga y no ellos". Yo le dije a mi mamá: "Están haciendo exactamente lo mismo que la iglesia católica“. Bueno, mi papá fue el que le dijo y fue cuando mi papá dijo: "los voy a sacar de ahî". A mí y a mi hermana nunca nos hicieron nada; mi hermana no iba de campamentos porque mi papá no quería y yo como hombre siempre fui más salvaje. Entonces mi papá se enteró de eso y ya fue como nuestro desenamoramiento de la Iglesia, porque critican mucho a la Iglesia católica en esta religión y cometen siempre los mismos errores que en la Iglesia católica. (Rodrigo, comunicación personal, 8 de agosto del 2018).

Finalmente, Rodrigo ingresó a un grupo masón en Tijuana y no ocultó el hecho, además de solicitar verbalmente su renuncia.

Ramírez, R. y Odgers, O. (2021). El costo de disentir: análisis de experiencias de ruptura de exmiembros de tres iglesias protestantes. Revista Cultura y Religión, 15(2), 210-243. 
Raquel (Testigo de Jehová)

Raquel es una mujer divorciada, de 39 años, madre de tres hijos. Fue educada como Testigo de Jehová desde su infancia. Su padre funge como anciano de congregación y, en otros momentos, ha ostentado cargos como superintendente de circuito y distrito.

Los primeros instantes de fricción que narra Raquel surgieron cuando ella tenía 15 años, momento en que comenzó a tener dudas sobre las creencias religiosas. Al ser una persona extrovertida, con facilidad estrechaba lazos de amistad con vecinos y compañeros de escuela que no pertenecían a la Iglesia. Explica que esta socialización con miembros externos le valió ser reconvenida sobre sus relaciones afectivas. Sintió que era una restricción autoritaria y excesiva que decidieran con quién podía o no confraternizar, y que desautorizaran a sus amigos solo por no pertenecer a la misma Iglesia, por lo que decidió desobedecer abiertamente dichas recomendaciones. A los 20 años tuvo una relación extramarital y quedó embarazada, por lo que fue expulsada de la congregación. Ese fue el punto de ruptura definitiva.

Pese a los conflictos que ya había expresado, la expulsión la llevó a una crisis personal. El distanciamiento de las creencias, exacerbado por la expulsión, la llevó con el tiempo a desarrollar críticas que ha externado con su familia, conocidos y en redes sociales. En particular cuestiona las doctrinas sobre la transfusión, el saludo a la bandera y el trato a los expulsados por parte del resto de los miembros de la Iglesia. Previo a su expulsión también había sido censurada por la sexualidad extramarital, el consumo de drogas, sus accesorios de moda y por haberse tatuado.

En su relato, no es claro si es una consecuencia directa de esta ruptura o del conjunto de etapas disruptivas en su vida (dos divorcios, así como problemas económicos y legales), pero señala que desde su expulsión de la Iglesia ha tenido la necesidad de recibir atención psicológica por problemas de adicciones, sentimientos de pérdida y ansiedad.

Ramírez, R. y Odgers, O. (2021). El costo de disentir: análisis de experiencias de ruptura de exmiembros de tres iglesias protestantes. Revista Cultura y Religión, 15(2), 210-243. 


\section{Alonso (Testigo de Jehová)}

Alonso es originario de Tijuana, tiene 31 años y vive en unión libre con su pareja. Narra que fue educado por su madre en las creencias de los Testigos de Jehová. Aunque nunca llegó a bautizarse, sí ocupó el puesto de publicador activo durante seis años y participaba con frecuencia en las actividades colectivas: asistencia a las cinco reuniones semanales, a las asambleas de distrito, circuito y días especiales, a las conmemoraciones, concurría asiduamente a la predicación en las calles, eventos deportivos, recreativos y de construcción, organizados por miembros de su congregación local.

El inicio de su desprendimiento se debió a la expulsión de su hermana de la misma Iglesia. Narra que, de acuerdo con las normas de la congregación, él tendría que haber roto toda relación con ella. Sin embargo, consideró inadecuado negarle la palabra y cuestionó la norma según la cual debe cortarse toda relación social con los que han sido expulsados.

De las razones por las cuales ya no regresé fueron algunas creencias en la doctrina como: el no querer o el no poder transfundir sangre... para mí no hay fundamento suficiente para que un hermano se abstenga de sangre y pierda la vida, o que decida por un hijo, ¿verdad? Ese tipo de cosas fueron un factor muy importante. (...) Esa fue una, otra: sus métodos de disciplina a mí no me gustaron. Todos somos pecadores, todos cometemos pecados, cometemos errores. Pero, el hecho de que se te censure públicamente, el hecho de que se te expulse públicamente y se te aparte de la congregación y se te niegue la palabra... que se te aparte durante un tiempo hasta que muestres arrepentimiento que es muy subjetivo, ¿verdad? Uno, las transfusiones de sangre, y dos, sus métodos de disciplina. Pudiéramos adentrarnos en más detallitos, pero esos fueron los principales factores para que ya no regresara. (Alonso, comunicación personal, 02 julio de 2018).

Así, en el relato de Alonso la experiencia concreta en relación con su hermana lo llevó a cuestionar una norma general; criticó ante los ancianos los métodos disciplinarios para sancionar a los infractores, incluidos regaños, destituciones de puestos de servicio (publicador, precursor, ministerial, etc.), censura (pública o privada) y expulsión. Posteriormente, emitió críticas sobre la

Ramírez, R. y Odgers, O. (2021). El costo de disentir: análisis de experiencias de ruptura de exmiembros de tres iglesias protestantes. Revista Cultura y Religión, 15(2), 210-243. 
prohibición de las transfusiones sanguíneas en casos de emergencia y de no participar en los honores a la bandera en las ceremonias oficiales. Como consecuencia, fue destituido como publicador. Tiempo después su madre también tomó distancia de la Iglesia, en parte, como consecuencia del trato dado hacia su hija expulsada y su hijo destituido.

\section{La gestación del disenso: de la ruptura y sus consecuencias}

Como puede observarse en los relatos antes presentados, aunque los motivos que inician el disenso están anclados en experiencias personales, en todos los casos, los relatos pasan de la anécdota personal a la crítica general de las normas de la Iglesia y de las formas de actuación de sus dirigentes.

$\mathrm{Si}$ bien en algunos casos el disenso viene acompañado de cuestionamientos teológicos, con más frecuencia los conflictos son terrenales y se relacionan con el trato recibido por parte de los dirigentes, con las restricciones a sus comportamientos, o la imposición de normas que consideran excesivas. En consecuencia, la ruptura con la iglesia no en todos los casos viene acompañada de un abandono de la fe. Es decir, su posicionamiento actual correspondería al descrito por Davie (1990) como "believing without belonging".

En la Tabla 1 se detalla el tiempo en que los participantes se mantuvieron como miembros activos en las iglesias con las que posteriormente disintieron; se refiere la forma en cómo se definen ellos mismos respecto a dichas iglesias y se señalan las creencias con las que actualmente se identifican. En todos los casos estudiados, los actos disidentes llevaron a la ruptura, por lo que ya no forman parte de sus iglesias de referencia, ya sea que tengan un estatus de desasociado, expulsado o destituido.

Ramírez, R. y Odgers, O. (2021). El costo de disentir: análisis de experiencias de ruptura de exmiembros de tres iglesias protestantes. Revista Cultura y Religión, 15(2), 210-243. 
Tabla 1: Iglesia de origen, tiempo de permanencia y desde la ruptura, y estatus actual

\begin{tabular}{lccccccc}
\hline Nombres Edad & $\begin{array}{c}\text { Escola- } \\
\text { ridad }\end{array}$ & $\begin{array}{c}\text { Religión de activos proceso } \\
\text { formación }\end{array}$ & $\begin{array}{c}\text { Añ la } \\
\text { Iglesia }\end{array}$ & $\begin{array}{c}\text { Años de } \\
\text { Postura } \\
\text { miento actual }\end{array}$ & $\begin{array}{c}\text { Estatus } \\
\text { autodefinido } \\
\text { ante la Iglesia }\end{array}$ \\
\hline Hernán & 47 & Posgrado & Adventista & 20 & 6 & $\begin{array}{c}\text { Creyente } \\
\text { independiente }\end{array}$ & Expulsado \\
\hline Rodrigo & 31 & Licenciatura Adventista & 18 & 7 & $\begin{array}{c}\text { Creyente } \\
\text { independiente }\end{array}$ & Expulsado \\
\hline Antonio & 37 & Posgrado & $\begin{array}{c}\text { IJSUD } \\
\text { (Mormón) }\end{array}$ & 15 & 7 & Ateo. & $\begin{array}{c}\text { Desasociado } \\
\text { Apóstata }\end{array}$ \\
\hline Erika & 27 & Licenciatura & $\begin{array}{c}\text { IJSUD } \\
\text { (Mormón) }\end{array}$ & 18 & 5 & $\begin{array}{c}\text { Libre } \\
\text { pensadora. } \\
\text { Agnóstica. }\end{array}$ & Desasociada \\
\hline Raquel & 39 & Secundaria & $\begin{array}{c}\text { Testigo de } \\
\text { Jehová }\end{array}$ & 19 & 7 & $\begin{array}{c}\text { Creyente } \\
\text { independiente }\end{array}$ & Expulsada \\
\hline Alonso & 31 & Licenciatura & $\begin{array}{c}\text { Testigo de } \\
\text { Jehová }\end{array}$ & 6 & 5 & $\begin{array}{c}\text { Creyente } \\
\text { independiente }\end{array}$ & $\begin{array}{c}\text { Publicador } \\
\text { destituido }\end{array}$ \\
\hline
\end{tabular}

Fuente: elaboración propia basada en entrevistas.

Dentro de la información aportada en los relatos, destaca la amplitud del tiempo que transcurrió entre las primeras dudas o inconformidades hasta la fecha de la ruptura definitiva: en el caso del proceso más rápido transcurrieron cinco años, y siete en el más extenso. De esta forma, las narraciones concuerdan con la perspectiva de la carrera o trayectoria creyente (Gooren, 2010): la disidencia es un largo proceso que comienza con dudas teológicas o desacuerdos terrenales, que van desarrollándose, se estructuran e irrumpen en momentos coyunturales. En algunos casos (Hernán, Rodrigo) se da un distanciamiento paulatino antes de la crisis y ruptura, mientras que en otros casos (Antonio, Raquel) el disenso crece y se estructura sin alejamiento, previo a la ruptura. Pero conviene insistir en que, en todos los casos, estamos lejos de un proceso paulino, aun si algunas crisis pueden aparecer de manera súbita.

Asimismo, conviene observar que el proceso de distanciamiento no necesariamente termina con la salida de la Iglesia. Antonio explica cómo la

Ramírez, R. y Odgers, O. (2021). El costo de disentir: análisis de experiencias de ruptura de exmiembros de tres iglesias protestantes. Revista Cultura y Religión, 15(2), 210-243. 
ruptura con la congregación fue solo una etapa en su trayectoria hacia el desprendimiento de la fe:

La idea de Dios me la desprendí después de cinco, seis o siete años después de dejar de asistir de la Iglesia; fue difícil, pero..., así fue; creo que fue un proceso largo para que esta idea que ya tenía totalmente interiorizada desapareciera; ya no tener miedo o no tener zozobra o no tener dudas. (Antonio, comunicación personal, 21 de enero del 2018)

La etapa previa a la ruptura se caracteriza por una tensión entre elementos que los retienen en la comunidad religiosa, y los que fortalecen el disenso y empujan hacia la ruptura. Estos elementos pueden ser de carácter religioso, pero pueden ser también de carácter social, como los conflictos interpersonales, o las relaciones afectivas o de amistad desarrolladas con otros miembros de la comunidad religiosa. Destaca que en todos los casos el componente no religioso, que resultó ser el más importante disuasor para la ruptura, fueron los lazos familiares. Los entrevistados consideran que el tener algún pariente cercano involucrado con las iglesias de las cuales disintieron, los llevó a retardar su salida y a ser menos críticos con las instituciones religiosas al momento de la ruptura.

Pero más importante aún es el hecho de que en todos los casos asocian esta relación, con las pérdidas sociales que significó su salida. Dicho de otra forma: retrasaron la ruptura por temor a las represalias que se expresarían como la pérdida de vínculos con familiares y amigos, y dicha pérdida de vínculos, en mayor o menor medida, efectivamente sucedió. Así, en todos los casos consideran que la principal consecuencia negativa de la ruptura fueron las pérdidas sociales (pérdida de relaciones afectivas con familiares y amigos), y en menor medida, pérdidas simbólicas (de prestigio o estatus). En la mayoría de los casos consideran que dichas pérdidas les provocaron problemas emocionales y psicológicos, de duración variable.

El temor a la pérdida de vínculos afectivos fue señalado efectivamente como el aspecto más difícil de encarar tras la ruptura. La pérdida de esas

Ramírez, R. y Odgers, O. (2021). El costo de disentir: análisis de experiencias de ruptura de exmiembros de tres iglesias protestantes. Revista Cultura y Religión, 15(2), 210-243. 
relaciones es percibida como la verdadera y más poderosa sanción que recibieron por el acto de disentir.

En la Tabla 2 se presenta de manera esquemática la relación de vínculos familiares, pérdidas sociales y simbólicas, y los problemas emocionales/psicológicos referidos por los entrevistados.

Tabla 2: Vínculos familiares, pérdidas sociales, simbólicas y emocionales

\begin{tabular}{ccccc}
\hline Nombres & $\begin{array}{c}\text { Familiares } \\
\text { dentro de la } \\
\text { Iglesia }\end{array}$ & $\begin{array}{c}\text { Pérdidas } \\
\text { sociales }\end{array}$ & $\begin{array}{c}\text { Pérdidas } \\
\text { simbólicas. }\end{array}$ & $\begin{array}{c}\text { Problemas } \\
\text { emocionales/ } \\
\text { psicológicos }\end{array}$ \\
\hline Hernán & Sí, su madre. & $\begin{array}{c}\text { Sí, } \\
\text { convivencia. }\end{array}$ & $\begin{array}{c}\text { No que le } \\
\text { importen. }\end{array}$ & $\begin{array}{c}\text { No, tenía grupos de } \\
\text { convivencia } \\
\text { externos. }\end{array}$
\end{tabular}

\begin{tabular}{|c|c|c|c|c|}
\hline Rodrigo & Sí, su madre. & $\begin{array}{c}\text { Sí, } \\
\text { convivencia. }\end{array}$ & Piensa que no. & $\begin{array}{c}\text { Sí. Desaparecieron } \\
\text { con los meses. }\end{array}$ \\
\hline Antonio & $\begin{array}{l}\text { Sí, familia } \\
\text { nuclear y } \\
\text { materna. }\end{array}$ & $\begin{array}{c}\text { Sí, } \\
\text { convivencia } \\
\text { de familia y } \\
\text { amistades. }\end{array}$ & $\begin{array}{l}\text { Sí, afirma que } \\
\text { no le afecta. }\end{array}$ & $\begin{array}{l}\text { Sí. Desaparecieron } \\
\text { con los meses. }\end{array}$ \\
\hline
\end{tabular}

\begin{tabular}{|c|c|c|c|c|}
\hline Erika & Sí, familia. & $\begin{array}{c}\text { Sí, } \\
\text { convivencia. }\end{array}$ & $\begin{array}{l}\text { Sí, afirma que } \\
\text { no le afecta. }\end{array}$ & $\begin{array}{c}\text { Recibe atención } \\
\text { psicológica y } \\
\text { psiquiátrica. }\end{array}$ \\
\hline Raquel & $\begin{array}{l}\text { Sí, familia } \\
\text { nuclear y } \\
\text { extendida. }\end{array}$ & $\begin{array}{c}\text { Sí, } \\
\text { convivencia } \\
\text { familiar y } \\
\text { amistades. }\end{array}$ & $\begin{array}{l}\text { Sí, estima y } \\
\text { respeto. }\end{array}$ & $\begin{array}{c}\text { Sí, permanecen. } \\
\text { Atención } \\
\text { psicológica. }\end{array}$ \\
\hline Alonso & Sí, familia. & $\begin{array}{c}\text { Sí, } \\
\text { convivencia. }\end{array}$ & $\begin{array}{l}\text { Sí. No fue } \\
\text { drástico. }\end{array}$ & $\begin{array}{c}\text { Sí, desaparecieron } \\
\text { con los meses. }\end{array}$ \\
\hline
\end{tabular}


Frecuentemente, las sanciones que se imponen a quien sale de la Iglesia, recaen también sobre su familia nuclear. Raquel, por ejemplo, señala: "Le dijeron a mi papá que si no había podido educar a su hija dentro del pueblo de Jehová, entonces ¿cómo iba a poder ser anciano de la congregación?” (Raquel, comunicación personal, 14 de enero del 2018). Alonso refuerza el punto anterior al explicar que cuando hay un miembro de la familia expulsado, el resto de la comunidad religiosa perteneciente a los Testigos de Jehová debe dejar de frecuentar dicho hogar, haciendo extensiva la sanción a su familia nuclear, para presionar a que la persona expulsada se restablezca en la Iglesia o abandone la vivienda. Por ello afirmó que bajo este escenario, los Testigos de Jehová son "una religión que separa a las familias" (Alonso, comunicación personal, 02 julio de 2018).

En este mismo sentido, en algunos relatos, los entrevistados recuerdan haber lastimado a sus seres queridos, como en el caso de Antonio:

Mis padres sí, sí pasaron un periodo de tristeza, de decepción, de desilusión. Sí, sí, sí... Mi mamá, ahorita que lo recuerdo, sí lloraba, lloraba porque su hijo ya no iba. No eran prácticas muy ofensivas, pero sí. Eso se puede interpretar como un chantaje emocional al cual nunca cedí. Pero me pareció que era auténtico su sufrimiento. Y mi padre un poquito más light, pero también mostraba desilusión. (Antonio, comunicación personal, 21 de enero del 2018).

En otros casos, la separación se hizo más ligera, debido al reemplazo de redes sociales con amistades establecidas previamente con personas ajenas a la iglesia.

Cuando yo dejo de ir a la Iglesia, te digo, fue muy paulatino, pero al final, yo ya tenía sustento fuera de la Iglesia. (...) Como te digo, yo siempre viví en dos mundos, yo tenía mi mundo dentro de la Iglesia y tenía mi mundo fuera de la Iglesia. Y de lunes a viernes, pues había veces que sí iba a la iglesia entre semana, pero entre semana yo vivía fuera de la Iglesia. (Hernán, comunicación personal, 19 de febrero del 2018)

Ramírez, R. y Odgers, O. (2021). El costo de disentir: análisis de experiencias de ruptura de exmiembros de tres iglesias protestantes. Revista Cultura y Religión, 15(2), 210-243. 
Como es natural, las consecuencias de la ruptura fueron más difíciles de sobrellevar para quienes, siguiendo las normas impuestas, mantenían la casi totalidad de sus relaciones afectivas con miembros de la Iglesia.

Respecto al origen de los actos disidentes, notamos que una característica previa del proceso disidente fue el acercamiento que tuvieron los entrevistados con los líderes de sus antiguas iglesias con el fin de expresar sus dudas, desacuerdos o crisis personales. Sin embargo, relatan que no sintieron que sus necesidades, dudas o cuestionamientos fueran satisfechos por sus guías espirituales o por las comunidades religiosas en general, por lo que los actos disidentes fueron una reacción o protesta como un resultado último de desencanto ante dichas insatisfacciones irresueltas.

Los actos disidentes constantes en los relatos de los entrevistados fueron las protestas verbales y el abandono de las iglesias. Los motivos primarios que, al ser desatendidos, dieron lugar a los actos disidentes fueron crisis personales, desacuerdos con dirigentes o miembros de la Iglesia, y dudas teológicas. Con el enfriamiento de su fe, los actos transgresores fueron apareciendo, muchos de estos actos llegando al grado de la disidencia, que dio lugar a la ruptura, ya sea en la forma de abandono de la iglesia, o de expulsión.

En la Tabla 3 se presenta de manera esquemática la relación del origen primario de la disidencia, y los actos disidentes relatados por los entrevistados. 
Tabla 3: Origen primario de la disidencia y actos disidentes

\begin{tabular}{|c|c|c|c|}
\hline Nombre & $\begin{array}{l}\text { Origen del } \\
\text { acto } \\
\text { disidente, } \\
\text { categoría: }\end{array}$ & $\begin{array}{l}\text { Origen del acto } \\
\text { disidente, } \\
\text { dimensión: }\end{array}$ & Actos disidentes como reacción: \\
\hline Hernán & $\begin{array}{c}\text { Actos de } \\
\text { dirigentes } \\
\text { Desacuerdos }\end{array}$ & $\begin{array}{l}\text { Doble moral de } \\
\text { dirigentes y } \\
\text { miembros } \\
\text { Desacuerdos con } \\
\text { actos de dirigentes }\end{array}$ & $\begin{array}{l}\text { Consumo de alcohol, asistencia a } \\
\text { centros nocturnos, protesta verbal } \\
\text { (expulsión), relación homosexual } \\
\text { con la cual asistía a la Iglesia }\end{array}$ \\
\hline Rodrigo & $\begin{array}{c}\text { Actos de } \\
\text { dirigentes } \\
\text { Desacuerdos }\end{array}$ & $\begin{array}{l}\text { Doble moral de } \\
\text { dirigentes y } \\
\text { miembros } \\
\text { Desacuerdos con } \\
\text { actos de dirigentes } \\
\end{array}$ & $\begin{array}{c}\text { Protesta verbal por ocultamiento } \\
\text { de abusos sexuales, violación } \\
\text { deliberada de la dieta alimentaria } \\
\text { en eventos de la Iglesia, renuncia } \\
\text { voluntaria (expulsión) } \\
\end{array}$ \\
\hline Antonio & $\begin{array}{l}\text { Dudas } \\
\text { teológicas }\end{array}$ & $\begin{array}{l}\text { Origen divino de la } \\
\text { Iglesia } \\
\text { Normatividad con } \\
\text { interpretación } \\
\text { humana } \\
\text { Rechazo al servicio } \\
\text { misionero } \\
\end{array}$ & $\begin{array}{c}\text { Protesta verbal sobre la ambición } \\
\text { de poder del clero mormón, el } \\
\text { manejo de salarios y diezmos. } \\
\text { Negación de servir como } \\
\text { misionero. Abandono deliberado } \\
\text { Apostasía }\end{array}$ \\
\hline Erika & $\begin{array}{l}\text { Dudas } \\
\text { teológicas }\end{array}$ & $\begin{array}{c}\text { Falta de comprensión } \\
\text { de lo sagrado } \\
\text { Origen divino de la } \\
\text { Iglesia }\end{array}$ & $\begin{array}{c}\text { Protesta verbal sobre } \\
\text { restricciones de pareja, falta de } \\
\text { equidad de género y escasa } \\
\text { capacitación de los líderes. } \\
\text { Propaganda antirreligiosa en } \\
\text { redes sociales. Desobediencia } \\
\text { general a alimentación, música, } \\
\text { vestimenta, etc. } \\
\text { Abandono deliberado }\end{array}$ \\
\hline Raquel & $\begin{array}{l}\text { Dudas } \\
\text { teológicas } \\
\text { (crisis } \\
\text { personal) }\end{array}$ & $\begin{array}{l}\text { Sangre, saludo a la } \\
\text { bandera y } \\
\text { excomunión } \\
\text { Madre soltera y } \\
\text { problemas familiares }\end{array}$ & $\begin{array}{c}\text { Protesta verbal sobre uso de } \\
\text { sangre y trato a excomulgados. } \\
\text { Sexualidad extramarital, } \\
\text { consumo de drogas, tatuaje } \\
\text { (expulsión). Crítica en redes } \\
\text { sociales }\end{array}$ \\
\hline Alonso & $\begin{array}{l}\text { Dudas } \\
\text { teológicas }\end{array}$ & $\begin{array}{c}\text { Sangre, saludo a la } \\
\text { bandera y } \\
\text { excomunión } \\
\text { Desacuerdo } \\
\text { interpretativo }\end{array}$ & $\begin{array}{l}\text { Protesta verbal sobre uso de } \\
\text { sangre, saludo a la bandera, trato } \\
\text { a expulsados y por la expulsión } \\
\text { un año antes de su hermana } \\
\text { Destitución pública de publicador }\end{array}$ \\
\hline
\end{tabular}

Fuente: elaboración propia basada en entrevistas.

Ramírez, R. y Odgers, O. (2021). El costo de disentir: análisis de experiencias de ruptura de exmiembros de tres iglesias protestantes. Revista Cultura y Religión, 15(2), 210-243. 
Aunque una buena parte de las consecuencias de enfrentar a las estructuras de poder clerical resultaron ser negativas, en particular en la etapa inmediatamente posterior a la ruptura, también se presentan en los relatos algunos beneficios como consecuencia de tomar distancia de los grupos religiosos. Entre estos: la libertad de decisión sobre sí mismos, sobre sus cuerpos, su alimentación, sus estilos de vida, sus gustos estéticos (arreglo personal, música), y sus prácticas sexuales; percatarse de la falta de equidad de género que había al interior de sus iglesias; alejarse de personas que describen como hipócritas o con doble moral; dejar de gastar parte de sus recursos económicos y tiempo personal en la Iglesia; desarrollar un pensamiento crítico sin miedo, y, de manera más general, un sentimiento de libertad y de haber salido de un mundo ficticio. Antonio y Rodrigo lo describen:

Ha mejorado (mi vida), para mí ha mejorado muchísimo. Para empezar, me junto con gente que no es religiosa, que no es hipócrita. Cuando yo estuve dentro de la Iglesia todo era una hipocresía muy grande, pero ya fuera es otra cosa, afuera todos se comportan de manera muy diferente. Y, yo ya estaba harto de eso... era andar a escondidas, o nada más en los campamentos. Entonces yo ya me quería deshacer de eso cuando salgo al mundo real. (...) (Rodrigo, comunicación personal, 8 de agosto de 2018).

El miedo, yo creo que perdí el miedo. Fue lo único que perdí (al abandonar la Iglesia). No siento ningún remordimiento, ni lo tuve en el pasado y no creo que lo vaya a tener en el futuro, no siento eso. No me imagino en qué circunstancia. (Antonio, comunicación personal, 21 de enero de 2018).

\section{A manera de conclusión}

Al analizar los datos recolectados, encontramos que el distanciamiento de los grupos religiosos fue un proceso paulatino, mientras que los principales detonantes de los actos disidentes fueron las dudas teológicas, las crisis personales y los desacuerdos irresueltos con la actuación de líderes y miembros

Ramírez, R. y Odgers, O. (2021). El costo de disentir: análisis de experiencias de ruptura de exmiembros de tres iglesias protestantes. Revista Cultura y Religión, 15(2), 210-243. 
de las iglesias. Las repercusiones para los disidentes dependieron de los grupos religiosos a los que pertenecían y de los vínculos (parentesco y amistades) que mantenían dentro y fuera de los círculos religiosos.

El tiempo de duración en los procesos de disidencia/ruptura religiosa puede estar vinculado con la temporalidad necesaria para transformar los esquemas cognitivos, ya que todos los sujetos de estudio fueron adoctrinados desde su infancia temprana en las creencias y prácticas de la iglesia.

La recuperación de las pérdidas sociales, simbólicas y emocionales, se relaciona con las redes de relaciones sociales que tenían al momento de sus rupturas. Es probable que también el perfil psicosocial de los sujetos sea un factor central para reconstruir relaciones sociales (sociabilidad) y la adaptabilidad al cambio (resiliencia).

Las pérdidas vinculadas con la red de relaciones sociales al momento de sus rupturas apuntan a que los entrevistados más inmersos en los círculos religiosos, con redes de amistad fuertes dentro de las iglesias y careciendo de vínculos sociales estrechos al exterior de las comunidades de fe, resultaron ser los más afectados. Esta situación puede ser aún más acentuada entre quienes mantienen relaciones laborales con los miembros de la iglesia. La red de apoyo externo, con la que solamente algunos contaban, también resultó ser un elemento fundamental para dar sustento emocional, apoyar el proceso de redefinición identitaria y la integración a nuevos grupos sociales.

La religión de origen de los entrevistados influyó en las consecuencias de la disidencia. La forma de enfrentar y sancionar la crítica varía dependiendo de cada Iglesia aun cuando es muy estricto en las tres iglesias bíblicas no evangélicas aquí consideradas. Es por ello que, un mismo tipo de acto, cometido al interior de denominaciones religiosas diferentes, tuvo consecuencias muy distintas para el sujeto transgresor, dependiendo de la institución religiosa en la que se realizó.

La relación que la congregación establece con quienes abandonaron la Iglesia tras la expresión de la disidencia varía notablemente, dependiendo de la

Ramírez, R. y Odgers, O. (2021). El costo de disentir: análisis de experiencias de ruptura de exmiembros de tres iglesias protestantes. Revista Cultura y Religión, 15(2), 210-243. 
denominación de la que se trate. Los adventistas resultaron ser más flexibles con sus miembros expulsados, enviando frecuentes cartas de reconciliación y saludándolos cordialmente en espacios públicos. A diferencia de ellos, los mormones excomulgados recibían el saludo solamente por parte de algunos segmentos de sus antiguas congregaciones, mientras que otros miembros les negaban la palabra cuando se encontraban en el espacio público. El caso más extremo fue el registrado con los Testigos de Jehová, quienes les negaron la palabra a los expulsados de su fe de manera sistemática.

A pesar de que no fue detectado un común denominador sobre las consecuencias de realizar actos disidentes, los factores asociados a ellas que han sido descritos podrían englobarse en: la asociación religiosa de pertenencia, el círculo de amistades que tenían dentro y fuera de la Iglesia al momento del acto disidente, la integración a nuevos grupos sociales donde resultaron aceptados una vez que se distanciaron de la Iglesia, el contexto sociocultural, las relaciones de parentesco y el perfil psicosocial de cada individuo.

Respecto al contexto sociocultural, conviene señalar que el habitar en una ciudad con diversidad cultural y religiosa amplía el espectro de posibilidades de desarrollo social para el individuo que abandona a una comunidad religiosa. Una atmósfera sociocultural plural alimenta dudas, críticas e ideas; promueve la tolerancia y la aceptación del que piensa distinto. Mientras un clima sociocultural hostil, o con escasa pluralidad religiosa, podría inhibir la disidencia y dificultar aún más el proceso de readaptación del disidente. El clima social de pluralidad cultural de la ciudad; la diversidad religiosa; la heterogeneidad de creencias, ideas y opiniones; los intercambios transfronterizos y entrar en contacto con distintas formas de pensamiento, fueron algunos de los elementos que promovieron el pensamiento crítico hacia sus creencias religiosas, por parte de los entrevistados.

Sería conveniente, en futuras investigaciones, analizar el proceso de recuperación y reorganización de la vida social de los disidentes, considerando tanto la sociabilidad y la resiliencia, como la capacidad de agencia de quienes

Ramírez, R. y Odgers, O. (2021). El costo de disentir: análisis de experiencias de ruptura de exmiembros de tres iglesias protestantes. Revista Cultura y Religión, 15(2), 210-243. 
disienten. En particular, sería interesante observar si la recuperación es mejor entre los disidentes que asumen que la recuperación de sus pérdidas depende de sus propias acciones y se responsabilizan de su felicidad, con respecto a quienes interpretan que las circunstancias de vida y las estructuras de poder los han llevado a escenarios que no depende de ellos transformar.

\section{Referencias bibliográgficas}

Andrews, M. (2002). Narrative and life history. En M. Andrews, S. Shalater, C. Squire y A. Treacher, Lines of Narrative (pp. 77-80). Londres: Routledge.

Arroyo, M. (2004). Cambio cultural y cambio religioso: Tendencias y formas de religiosidad en la España de fin de siglo. Madrid: Universidad Complutense de Madrid.

Bruner, J. (2002). Making Stories: Law, Literature and Life. Nueva York: Farrar Strauss Giroux.

Cantón, M. (2009). Simbólica y política del diablo pentecostal. Cultura\&Religión, 3(1), 81-95.

Casillas, R. (1988). Emergencia protestante y disidencia religiosa en Chiapas. Estudios Fronterizos, (17), 105-131.

Corpus, A. (2014). ¿Como nuestros padres han creído? Jóvenes evangélicos y desafiliación eclesial en México. Cultura y Religión, 8(1), 30-46.

Davie, G. (1990). Believing without belonging: Is this the future of religion in Britain? Social Compass, 37(4), 455-469.

Durkheim, E. ([1912] 1995). Las formas elementales de la vida religiosa. Ciudad de México: Diálogo Abierto.

Garma, C. (2018). Conversión y movilidad religiosa, propuesta para su análisis. Cultura y Representaciones Sociales, 12(24) [En línea]. Recuperado de http://www.culturayrs.unam.mx/index.php/CRS/article/view/467/625

Ramírez, R. y Odgers, O. (2021). El costo de disentir: análisis de experiencias de ruptura de exmiembros de tres iglesias protestantes. Revista Cultura y Religión, 15(2), 210-243. 
Garma, C. y Odgers, O. (2021). Categorías para repensar la movilidad religiosa en México. En R de la Torre, C. Gutiérrez y A. Hernández, Reconfiguraciones de las identidades religiosas en México (pp. 79-102). México: El Colef/Ciesas.

Gooren, H. (2010). Religious Conversion and Disaffiliation: Tracing Patterns of Change in Faith Practices. Nueva York: Palgrave MacMillan.

Hernández, G. (2011). Conversiones religiosas e historia oral. Pentecostales y mormones en contextos migratorios, en Bahía Blanca y área de influencia. Cultura\&Religión, 5(1), 135-155.

Hernández-Madrid, M. (2000). El proceso de convertirse en creyentes. Identidades de familias testigos de Jehová en un contexto de migración transnacional. Relaciones. Estudios de historia y sociedad, 21(83), 6997.

Hervieu-Léger, D. (1993). La religion pour mémoire. París: Les éditions du CERF.

Hervieu-Léger, D. (1996). Por una sociología de las nuevas formas de religiosidad: Algunas cuestiones teóricas previas. En G. Jiménez, Identidades religiosas y sociales en México (pp. 23-45). México D. F.: IFAL-IIS-UNAM.

Instituto Nacional de Estadística y Geografía (INEGI) (2015). Clasificación de religiones 2010. México: INEGI. Recuperado de https://www.inegi.org.mx/contenidos/productos/prod_serv/contenidos/es panol/bvinegi/productos/nueva_estruc/702825064983.pdf

Medina, A. (2020). Narrativas de identidad islámica: universalismo, latinidades y nacionalismos para el caso de México y Estados Unidos. Cultura\&Religión, 14(1), 142-161.

Mora Duro, C. (2017). Entre la crítica, la autonomía y la indiferencia: la población sin religión en México. Estudos de Religião, 31(3), 157-178.

Rambo, L. (1993). Understanding Religious Conversion. New Heaven: Yale University Press.

Ramírez, R. y Odgers, O. (2021). El costo de disentir: análisis de experiencias de ruptura de exmiembros de tres iglesias protestantes. Revista Cultura y Religión, 15(2), 210-243. 
Revista Cultura y Religión Vol. XV, Nº 2 (julio-diciembre) 2021

Sánchez García, O., Plascencia Martínez, F. y Bernal Guzmán, L. G. (2020). Grupo de referencia etario, régimen simbólico y religiosidad. La religiosidad como sistema abierto de creencias en estudiantes universitarios. Cultura \& Religión, 14(2), 121-140.

Ramírez, R. y Odgers, O. (2021). El costo de disentir: análisis de experiencias de ruptura de exmiembros de tres iglesias protestantes. Revista Cultura y Religión, 15(2), 210-243. 